\title{
Performance e nostalgia na música brega
}

\section{Thiago Soares'e Pedro Alves}

\section{Resumo}

Performances nostálgicas são centrais para o entendimento das construções valorativas nas músicas populares periféricas brasileiras. O artigo busca analisar como a nostalgia é performatizada na música brega de Pernambuco, a partir de um debate que incide em reconhecer roteiros performáticos (TAYLOR, 2013) e acionamentos nostálgicos (BOYM, 2001) como forma de reinserção de artistas "esquecidos" no contexto de intensa jovialização do gênero musical. Centra-se o olhar sobre a banda Amigas do Brega, projeto que visa a reinserção de artistas "das antigas" nos mercados musicais local e nacional intensamente jovializado a partir da emergência das práticas digitais de consumo musical sobretudo após a consagração do bregafunk. Entende-se que a ausência de arquivos e de marcadores históricos da música brega opera sobre a disputa por espaços de memória em que a corporificação do passado atua como importante capital para artistas musicais. A análise centra-se num espetáculo registrado em DVD e disposto na plataforma de vídeos YouTube a partir das categorias de nostalgia restauradora e reflexiva, propostas por Boym (2001), apontando zonas tensivas entre memória e esquecimento nas negociações performáticas que emergem nas músicas populares periféricas brasileiras.

\section{Palavras-chave}

Música Pop; Nostalgia; Performance; Brega; Cultura Digital. 


\section{Performance and nostalgia in brega music}

\section{Thiago Soares'and Pedro Alves ${ }^{2}$}

\section{Abstract}

Nostalgic performances are central to the understanding of valuing constructions in Brazilian peripheral popular music. The article seeks to analyze how nostalgia is performed in the brega music of Pernambuco, based on a debate that focuses on recognizing performatic scripts (TAYLOR, 2013) and nostalgic actions (BOYM, 2001) as a way of reintegrating "forgotten" artists in the context intense jovialization of the musical genre mainly after the consacration of bregafunk in brazilian context. The focus is on the band Amigas do Brega, a project that aims to reintegrate artists from the "old" into the intensely youthful local and national music market as a result of the emergence of digital music consumption practices. It is understood that the absence of archives and historical markers of brega music affects the dispute for memory spaces in which the embodiment of the past operates as an important capital for musical artists. The analysis focuses on a show recorded on DVD and displayed on the YouTube video platform from the categories of restorative and reflective nostalgia, proposed by Boym (2001), pointing out tense zones between memory and forgetfulness in Brazilian peripheral popular music.

\section{Keywords}

Pop Music; Nostalgia; Performance; Brega; Digital Culture. 
Fenômeno cotidiano na cena musical do Recife desde a década de 1970, a música brega é uma das manifestações culturais mais presentes na periferia da capital pernambucana e sua região metropolitana, estendendo-se à margem de movimentos e modismos musicais, ausentes nas paradas de sucesso do mainstream e também fora dos radares da crítica musical. Em mais de 40 anos, o gênero musical passou por inúmeras transformações nas suas lógicas de produção, circulação e consumo trazendo implicações estéticas e políticas, evidenciando a predominância do consenso em torno do baixo valor musical deste cancioneiro, como observa Araújo (2015) ao detalhar as inúmeras classificações em torno da música romântica ouvida pelas classes populares que convergiam para a rotulação de "música cafona".

Observar a música brega através da clivagem dos marcadores de classe social auxilia na compreensão de como parte da detração da crítica musical e do jornalismo cultural em torno do cancioneiro brega advém de diferentes formas de exclusão das expressões populares das pautas e agendamentos da mídia. A invisibilidade da música brega opera sob a lógica da ausência de memória das expressões culturais produzidas nas periferias e nas áreas pobres das cidades brasileiras. Essa ausência que também se constrói à margem das políticas públicas em torno de músicas midiáticas periféricas. Para se ter um parâmetro da carência do poder público diante dos mecanismos de conservação da música brega, mesmo com o sucesso de um artista como Reginaldo Rossi - largamente chamado de "rei do brega", inclusive nacionalmente - artistas pertencentes a esse ramo musical não podiam se apresentar ou concorrer a editais públicos das secretarias de cultura do Governo de Pernambuco até o ano de 2017.

A capilarização da música brega na Região Metropolitana do Recife foi criando inúmeros constrangimentos em torno da seleção de atrações artísticas e musicais por curadores e integrantes das secretarias de cultura municipais e estaduais para festejos populares (Carnaval, festas juninas, entre outras). No dia 14 de fevereiro de 2017, o Projeto de Lei $n^{\circ} 8$ 1.176/2017 [1], deu origem à defesa da música brega como “expressão cultural pernambucana”, tendo sido aprovado em maio de 2017. Em 19 de agosto de 2017, a Lei $n^{0}$ 16.044/2017 é publicada no Diário Oficial do Estado, tendo sido aprovada por unanimidade na Assembleia Legislativa de Pernambuco. o que, em linhas gerais, a lei permite é que artistas de brega possam disputar verba pública para ocupar espaços em eventos financiados pelo Estado, ao lado de artistas de outras expressões da cultura popular como frevo, maracatu, ciranda, entre outros. Instaurase assim um debate sobre políticas públicas e o reconhecimento de diferentes matrizes da cultura popular: para além do popular folclórico, sintetizado pelas expressões culturais protegidas e incentivadas pelo Estado, existe um popular midiático que também funciona como dispositivo identitário e agregador de ideais culturais de um território. 
Diante de uma institucionalizada ausência de arquivos e dados sobre a música brega, instaura-se um problema para se desenvolver pesquisas acadêmicas sobre gêneros musicais oriundos das periferias brasileiras: os arquivos. As canções de brega parecem evanescer, muitas não estão dispostas em suportes (CDs, DVDs, bibliotecas digitais) - analógicos ou digitais - ficando presentes apenas na memória dos ouvintes. Integra aquilo que Diana Taylor (2012) chama de "repertório" do comum, do ordinário, um conhecimento que está corporificado e, como tudo aquilo inscrito no corpo, fadado a desaparecer.

A perspectiva da corporificação do conhecimento em torno da música brega provoca um debate ainda mais oportuno sobre a ausência de história das periferias, das classes subalternas, da cultura de sujeitos vulneráveis no Brasil. Reitera-se a metanarrativa histórica e performática dos hegemônicos, aquela contada pelas "histórias oficiais", localizadas por falantes "do centro", que olham com desdém para os sujeitos das bordas. A ausência de arquivos do cancioneiro brega reitera 0 lugar de não reconhecimento de uma estética, de uma forma cultural, a ponto de provocar questionamentos, no âmbito do senso comum e das redes sociais digitais, se manifestações da música brega "são cultura ou não" [2].

A ausência de memória sobre a música brega também implica em reinterpretações de dados, fatos e fenômenos. Tangenciando o esquecimento, são abertas possibilidades de reinvenções da memória, dos acionamentos performáticos e de "narrativizar" a própria história de um gênero musical. Artistas da música brega de diferentes gerações passam a reivindicar o "mito de origem" e se colocam no centro de uma atualização performática de suas histórias, apontando para disputas em torno do passado como retórica e posicionamento mercadológico.

Diante de um quadro em que os sentidos de passado e de memória passam a ser disputados e intensificados pelos sistemas de arquivamento nas redes sociais digitais e nas plataformas de áudio e vídeo, aciona-se aquilo que Hobsbawm e Ranger (1997) chamam atenção: o caráter fictício das tradições. Para além da invenção das tradições como um fator importante na formação das identidades nacionais na modernidade, opera-se a partir da reivindicação e da construção narrativa através de valores performaticamente construídos. A tradição passa a ser corporificada, roteirizada e encenada. Hobsbawm (1997, p. 9) chama de "tradições inventadas" as práticas usualmente reguladas por regras tácitas ou abertamente aceitas, de natureza ritual ou simbólica, que visam presentificar valores e normas de comportamento através da repetição, o que implica numa continuidade em relação ao passado. Para além das plataformas políticas das invenções e de sua natureza "oficial" (festas cívicas, heróis nacionais, bandeiras e hinos), o atravessamento performático das tradições operaria em torno do que Schechner (1985) denomina "comportamento restaurado", ou seja, "as sequências de ações que não são processos em si, mas correspondem a organizações de acontecimentos, roteiro de ações e movimentos codificados que se 
apresentam em sua presença” (SCHECHNER, 1985, p. 35-36).

Diante do quadro complexo em que o passado passa a ser disputado, performatizado e restaurado, este artigo propõe debater a performatização da nostalgia na música brega pernambucana, a partir do aparecimento e consagração do projeto Amigas do Brega, formado por quatro cantoras pernambucanas que fizeram sucesso especialmente na primeira década dos anos 2000, momento considerado de maior efervescência para a produção do "brega pop” em Pernambuco (FONTANELLA, 2005) e que se reúne no formato de "grupo de garotas" (girl group ou girl band [3]) dezessete anos depois, buscando nova inserção no mercado musical pernambucano e nacional.

Idealizado em meados de 2017, o projeto Amigas do Brega [4] surgiu a partir da união de cantoras da segunda geração [5] (SOARES, 2017) de artistas desse gênero musical, para a gravação de um DVD, com um "tributo" ao brega romântico. Tratavase, a princípio, de uma estratégia de reposicionamento dessas cantoras, que tinham gozado de relativo sucesso local, sobretudo até o ano de 2010, e diante de um amplo processo de jovialização da música brega pernambucana, a partir da consagração do bregafunk (SOARES \& BENTO, 2020). As canções escolhidas para este DVD foram chamadas pelo produtor e cinegrafista João Paulo Melo (responsável pela captação do audiovisual) de "brega das antigas" e tinham como princípio registrar os atos performáticos das cantoras em audiovisual para dispor em plataformas audiovisuais como o Youtube.

O grupo foi inicialmente formado por Palas Pinho, Dany Myler, Dayanne Henrique e Isa Falcão - essa última substituída por Eliza Mell menos de um ano após a formação do grupo. A cantora Palas Pinho, idealizadora do projeto, afirmou, em entrevista ao Jornal do Commercio (GOMES, 2018), que a ideia de criar as Amigas do Brega surgiu em meio a um descontentamento acerca do próprio destino das bandas e cantores da segunda geração do gênero (que segundo ela, estavam "esquecidos"), além de ser uma tentativa de resgatar um período específico do brega romântico. Para Pinho, a partir da chegada dos MCs e do bregafunk, criou-se uma cultura de competitividade no gênero musical, que teria fragilizado artistas "antigos".

O conjunto de reivindicações apontados pela idealizadora do projeto Amigas do Brega (resgate de artistas esquecidos, valorização do passado, importância da memória de um gênero musical, reposicionamento mercadológico) serve como epicentro para o debate sobre performatização da nostalgia nas músicas populares periféricas brasileiras, colocando em cena disputas simbólicas, reencenações e apagamentos a partir de tácitas zonas de contato temporais recolocadas midiaticamente no presente. É a partir de uma zona indefinida de marcos históricos e "oficiais" da música brega, que artistas vão performar a nostalgia na tentativa de reivindicação de relevância e construindo valores diante da consagração de outrora. Centra-se a análise do DVD "Amigas do Brega - As 4 Maiores Vozes de uma Geração", lançado em 2018 para ser 
divulgado no canal do YouTube do grupo musical.

O artigo está dividido em três partes. Na primeira, detalha-se a questão geracional na música brega de Pernambuco, a partir das disputas de gênero e de idade que se instauram diante de um intenso processo de jovialização desse ramo musical a partir da consagração do bregafunk, no ano de 2017 e o chamado "esquecimento" dos artistas do "brega das antigas". Na segunda parte, aposta-se numa metodologia sobre roteiros performáticos (TAYLOR, 2013) para se pensar o que chamamos de performatização da nostalgia, ou seja, a disposição cênica e corporal do passado como lugar privilegiado para a construção de roteiros midiáticos no contexto das redes sociais digitais. Na terceira parte, apresenta-se como o projeto Amigas do Brega provoca a nostalgia diante de diferentes quadros performáticos, em que a menção a outros artistas "antigos" do cancioneiro brega se amalgama a referências da música pop, em especial, às chamadas divas pop globais (SOARES; MANGABEIRA; LINS, 2021). Desenha-se a hipótese de que nas músicas populares periféricas, diante da ausência de arquivos e de ações dos poderes públicos e privados, o espaço da memória é disputado de forma a compor um quadro impreciso em que os espectros do passado encontram-se projetados em acionamentos mercadológicos e contextuais.

\section{A questão geracional nas músicas populares periféricas}

Chama-se música brega um conjunto heterogêneo de produção musical, envolvendo canções, álbuns fonográficos, artistas, produtores, gravadoras e selos do mercado musical e consumidores que orbitam em torno do cancioneiro romântico e popular, em que a marcação de classe social torna-se a principal chave de interpretação e rotulação, seja a partir da origem dos artistas ou dos ouvintes e dos espaços populares, em grande parte, periféricos por onde as canções circulam. A marcação de classe social no consumo cultural da música brega é um fator central para o reconhecimento das clivagens em torno da música romântica, como aponta Araújo (2010).

A música brega pode ser pensada a partir de diferentes acentos que assumiu em seus fluxos comunicacionais no território brasileiro. Distintos contextos de produção e consumo da música brega implicam em reconhecer as particularidades dos processos migratórios, das zonas fronteiriças e das redes comunicacionais na maneira com que o gênero musical se espraiou em diferentes contextos no Brasil. As particularidades de cada um dos contextos evidenciam tonalidades da música brega: 1. a chamada música cafona, com ampla circulação na região Sudeste (ARAÚJO, 2010) conecta este cancioneiro aos contingentes de migrantes no Sudeste brasileiro nas décadas de 1950 a 1970 (vindos das regiões Centro-Oeste, caso de Odair José e Amado Batista, de Goiás; e do Nordeste, com Waldick Soriano, saído do interior da Bahia), à forte presença do rádio e da indústria fonográfica voltada aos nordestinos e à marcação de classe 
social no consumo cultural; 2. ao tecnobrega, que ainda na década de 1970, na região Norte do Brasil, mais especificamente no Pará, mas também nas zonas fronteiriças do Amapá, Amazonas e de Roraima, ganha sonoridades, timbragens e poéticas de um conjunto de práticas musicais caribenhas, do calipso (AZEVEDO; JÁCOME; PRADO, 2019) e das sonoridades latinas (AMARAL, 2009; MELO; CASTRO, 2011), a partir das redes comunicacionais porosas em que rádios comerciais, "piratas" e vazamentos de sinais de comunicação em zonas fronteiriças implicam na circulação de canções e artistas em intensas trocas simbólicas entre países da América Latina e o Brasil; 3. à música brega do Nordeste brasileiro, que opera maciçamente em Pernambuco e mais amplamente no interior dos estados nordestinos, conecta-se a matrizes estéticas do forró e também se vale dos fluxos migratórios entre as regiões Norte e Nordeste do Brasil (SOARES, 2017) para a criação de matrizes sonoras e performáticas híbridas, diante de quadros comunicacionais em que as redes sociais digitais estabelecem vasos comunicantes entre artistas do Nordeste brasileiro e de países lusófonos da África (Angola, Moçambique e Cabo Verde).

É a partir do recorte sobre a música brega em Pernambuco que se desenha uma importante marcação na organização em torno das rotulações desse cancioneiro: a geracional. A primeira geração, conhecida como responsável por uma "onda" de músicas cafonas (ARAÚJO, 2002), teve, em Pernambuco, Reginaldo Rossi como principal expoente, e despontou no fim dos anos 1960 tendo se consagrado nas décadas de 1970 e 1980 no contexto nordestino. Centra-se principalmente na figura do homem romântico e sexual, com performances e canções que incidem cada vez mais em temas como a vida desregrada, traições e "bebedeiras", mas buscando um grande amor. As referências ao amor romântico e às versões de canções da Jovem Guarda posicionam essa primeira geração da música brega interseccionada a partir das dinâmicas de classe social e gênero.

Cerca de 30 anos depois do surgimento de Rossi, entra em cena uma geração de cantoras que se articulam no brega com uma espécie de "resposta aos cortejos masculinos" (SOARES, 2017, p. 42) e é próximo a esse movimento que a palavra brega não mais significa, necessariamente, cafona, apesar do teor melodramático existente no gênero musical. Essas cantoras, em palco, personificam a mulher que argumenta e questiona o homem, mas, ainda assim, cede aos seus apelos. Esse eixo, também chamado de "brega pop" (FONTANELLA, 2015), se articula sob a centralidade feminina e surge a partir de uma série de aproximações com o tecnobrega paraense, a partir da migração da Banda Calypso do Pará para Pernambuco e coincide, também, com o protagonismo feminino nos vocais das bandas do forró eletrônico cearense. É nessa fase que o brega alcança espaço na programação local das televisões pernambucanas, consagrando os programas de auditório que passam a ser articuladores centrais do gênero musical, tanto na circulação quanto, por vezes, na própria produção.

É a partir das disputas geracionais no brega, que uma terceira geração emerge, 
protagonizada pelos MCs (mestres de cerimônia, termo já amplamente popularizado no funk) ligados ao que se convém chamar de bregafunk. Esse terceiro eixo propõe uma volta do protagonismo masculino no gênero musical, mas de forma mais jovial e ainda mais sexualizada. Entram em cena, matrizes performáticas que dialogam com a ostentação do funk paulista e o imaginário sexual como forma de acionar jogos de sedução nas periferias. A forte presença das mídias sociais digitais impulsiona a carreira dos jovens cantores, especialmente por meio do YouTube e aplicativos de mensagens instantâneas como o WhatsApp. As parcerias com o comércio local e os anúncios nas redes sociais digitais formam um ecossistema propício tanto à consagração de jovens talentos da música brega quanto ao esquecimento de artistas consagrados.

É diante da fissura geracional na música brega de Pernambuco, a partir da consagração do bregafunk, que uma série de artistas passam a reivindicar o valor do passado e a autenticidade da música brega "das antigas" como posicionamento. Observa-se a estratégia de performar a nostalgia como uma tentativa de fuga ao esgotamento do mercado musical e o acionamento de públicos que se orientam tanto por valores mais “musicais", mas também morais no consumo cultural.

\section{Performar nostalgia}

Este complexo quadro das flutuações e reordenamentos da música brega a partir das dinâmicas comunicacionais permite perceber como a nostalgia emerge como roteiro performático (TAYLOR, 2013) para posicionamentos de artistas musicais. Por nostalgia (BOYM, 2001), entende-se o desejo "por um lar existencial não mais tangível”, no passado. É um sentimento de perda e deslocamento que também é, ao mesmo tempo, a fascinação pela própria fantasia [6]. Em seu livro dedicado ao tema, Svetlana Boym assegura que a nostalgia é uma experiência possibilitada por circunstâncias específicas da época moderna, em função de um certo esgotamento de formas anteriores de temporalidade ocidentais - a partir da teologia da salvação das sociedades cristãs que teria sido substituída pela centralidade do "novo" na cultura moderna. O passado, para a autora, vira essencialmente irrecuperável e irrepetível.

É possível pensar na sedução e no fascínio do conceito a partir da diferenciação que a autora faz entre nostalgia restauradora e reflexiva. Se a primeira busca uma reconstrução daquilo que se perdeu ou de uma certa realidade imaginada daquilo que teria sido o passado, a segunda baseia-se não numa reconstrução do que se foi, mas numa flexibilidade do passado em direção ao presente, em projeções e espectros comparativos. Busca-se, assim, não a mera recuperação do que é percebido como verdade, mas a mediação sobre a história, a passagem do tempo e a própria finitude dos fenômenos.

A dimensão nostálgica no brega apresenta-se entre a dinâmica reparadora, ou 
seja, retomar um determinado período histórico chamado por atores sociais como "melhor era da música brega", ao mesmo tempo que aciona a reflexividade, na medida em que permite "contaminar" o passado com ingerências do presente, aproximações com outros gêneros musicais e com outras esferas performáticas da cultura pop. A dimensão geracional fortemente ancorada na música brega modula-se na medida em que gerações passam a disputar o passado, o desejo por uma espécie de comunidade perdida, utopia ou contexto intangível que se intensifica pela efemeridade das figuras da indústria musical na era dos hits da internet nas músicas populares periféricas.

A reflexão sobre nostalgia articula-se às noções de melodrama, já amplamente utilizadas para estudos sobre culturas populares no Brasil e na América Latina. O teor melancólico, típico do melodrama cultuado abundantemente pelas culturas latino-americanas e periféricas (MARTÍN-BARBERO, 1997) adentra à música brega a partir da construção das canções como espaços especulativos de amor, saudade e sexualidade ("sacanagem"), em processos de enculturação a partir da reprodução de clichês consagrados da cultura. A forma com que atores sociais das classes populares se relacionam com o ideal romântico, segundo Martín-Barbero (1997), remonta ao ideal moral no qual se baseia a classe trabalhadora para experimentar o "ser" sob a égide do capitalismo, com a possibilidade de transgredir a dominação de classes hegemônicas por meio de pequenas situações-limite.

Debate-se nostalgia e melodrama como performances, ou seja, como uma clivagem, uma forma de conhecer culturas e sociedades, na qual o corpo ocupa papel central. A performance seria uma "lente metodológica" que desvelaria as teatralidades e encenações das culturas, a partir de configurações paradigmáticas que contam "com participantes, estruturados ao redor de um enredo esquemático, com um fim pretendido (apesar de adaptável)” (TAYLOR, 2013, p. 41). Dentro do amplo programa proposto por Taylor para os estudos de performance, recorta-se a noção de roteiro performático cuja proposição seria de estruturar um modode observaras performances midiáticas em redes sociais digitais e demais ambientes midiáticos como situações de encontros e desencontros, narrativas que se apresentam encenadas: um grupo de sujeitos e uma plateia, num cenário enunciativo, um contexto cultural. Debater uma metodologia de análise dos roteiros como uma forma de entender as culturas implica em reconhecer aquilo que está dentro dos quadros performáticos, mas, sobretudo, os "foras de quadros". Pensar através da ideia de roteiro nos fornece subsídios para reconhecer tanto o implícito das encenações (e tentar resgatá-los através de dados primários ou secundários), mas também aquilo que se coloca explícito, os clichês das encenações, sobretudo através dos estereótipos.

O que Taylor está reivindicando é parte do que Derrida (2001) também já mencionou: arquivos são sempre vivos e prontos para serem lidos a partir da perspectiva do presente, evocando uma dimensão processual da performance que apenas "parece" estática em sua relação com a história. Entretanto, é o fincar 
histórico que situa os arquivos menos como um reflexo do passado e mais como o que foi possível ser feito naquele contexto, que implicações existiam para que uma encenação fosse produzida do jeito que foi. Observar imagens arquivais a partir da perspectiva dos roteiros performáticos possíveis é, de acordo com Taylor (2013), um exercício metafórico em torno também das performances e ações cotidianas sempre reelaboradas e reconstruídas.

A partir dos indicativos de Taylor (2013), propomos pensar a performance dentro dos atravessamentos midiáticos: suas entradas, saídas e as permanências dos corpos na esfera das mídias. Como tais corpos se colocam em cena, o que teatralizam. A abordagem da performance precisa reconhecer a própria dinâmica midiática como uma camada performática. As mídias formam, em si, agenciamentos performáticos que indicam modos particulares de agir, olhar, interagir e valorar.

\section{Amigas do Brega, entre a reparação e a reflexão}

Com repertório composto por canções autorais e regravadas de outros artistas, o DVD das Amigas do Brega foi gravado em 2018, a partir de um show surpresa realizado em Nova Descoberta, periferia da zona norte do Recife e um dos "berços" de movimentações ligadas ao gênero musical, seja pelo surgimento de cantores ou mesmo por suas casas de show dedicadas quase completamente à música brega. Intitulado "Amigas do Brega - As 4 Maiores Vozes de uma Geração", a produção foi divulgada no início de 2019, no YouTube. O DVD foi uma estratégia de divulgação do canal das Amigas do Brega na plataforma de vídeos YouTube e, ao todo, foram publicados 18 vídeos, num intervalo de duas semanas [7]. A ideia de realizar um DVD para amparar as visualizações de um canal no YouTube aponta para os usos particulares da plataforma de vídeos pelos atores da música brega, bem como aponta para matrizes específicas do videoclipe nestes ecossistemas midiáticos.

Os primeiros usos do YouTube por artistas "das antigas" da música brega pernambucana foram da ordem de compartilhar trechos de apresentações em programas de auditório ao vivo na televisão pernambucana. Canais de YouTube [8] passam a se notarizar por burilar e publicar "relíquias" audiovisuais e vídeos nostálgicos com apresentações de artistas "esquecidos" em suas primeiras aparições nos programas de televisão locais. Os usos "nostálgicos" da plataforma de vídeos pelos atores sociais da música brega de Pernambuco apontam para aquilo que Montaño (2015) chama atenção ao tratar as plataformas de vídeos como ambientes que favorecem as relações entre dispositivos, usuários e arquivamentos diversos, evidenciando diferentes usos que apontam para recombinações, remontagens e "atualizações" de materiais arquivados.

A mescla de materiais de arquivo e também novos (ou recém-produzidos) nessas plataformas se reorganizam a partir de ingerências de algoritmos, em suas lógicas de 
recomendação e aproximação, fazendo com que sugestões "antigas" apareçam junto a "novas", promovendo um embaralhamento temporal que se assemelha à própria marca de ausência de memória e de dados sobre as músicas populares periféricas brasileiras. O "fatiamento" do DVD Amigas do Brega em 18 vídeos dispostos no YouTube sugere a atualização da própria noção de videoclipe, como propõe Pereira de Sá (2017), ao cunhar o termo "videoclipe pós-MTV" em que reconhece que a materialidade das redes sociotécnicas digitais permite postular uma outra ontologia deste audiovisual, em que trechos de shows, performances ao vivo e vídeos musicais sejam "enredados" nas lógicas das redes sociais digitais.

Um dos primeiros videoclipes a serem divulgados pelas Amigas do Brega foi o do ato performático da canção "Em Plena Lua de Mel", que marcou a carreira do cantor Reginaldo Rossi. A faixa aparece "repaginada" agora com as quatro cantoras interpretando a canção, com um arranjo com "toques" modernos, como o uso de guitarras e sopros. Ainda com os vocais de Isa Falcão, elas se apresentaram numa casa de shows do Recife, usando vestidos estampados com diferentes momentos da carreira de Rossi (Imagem 1). O tributo ao "rei do brega" passa a ser um constante lembrete da proposta das cantoras ao formar o grupo: relembrar o passado a partir de uma nostalgia reparadora (BOYM, 2001), ou seja, a reiteração de marcos históricos e performáticos que se dão a partir dos corpos e das suas encenações. Ao se conectar a Reginaldo Rossi, as cantoras estabelecem uma política de cordialidade e reverência aos "antigos", demarcando linhas discursivas que aproximam diferentes gerações do brega a partir da questão etária.

Na legenda de uma foto publicada em seu Instagram [9], a integrante Dany Myler diz que as Amigas do Brega homenageiam "uma geração de ouro interpretando as suas canções" (GOMES, 2018) e que as quatro formam o projeto "em respeito aos artistas que realmente vivem para defender esse estilo tão nosso, sem máscaras, sem ego inflado, sem arrogância e principalmente sem falsidade", referindo-se às rivalidades experienciadas dentro do gênero musical, a partir da “jovialização” do gênero musical. 


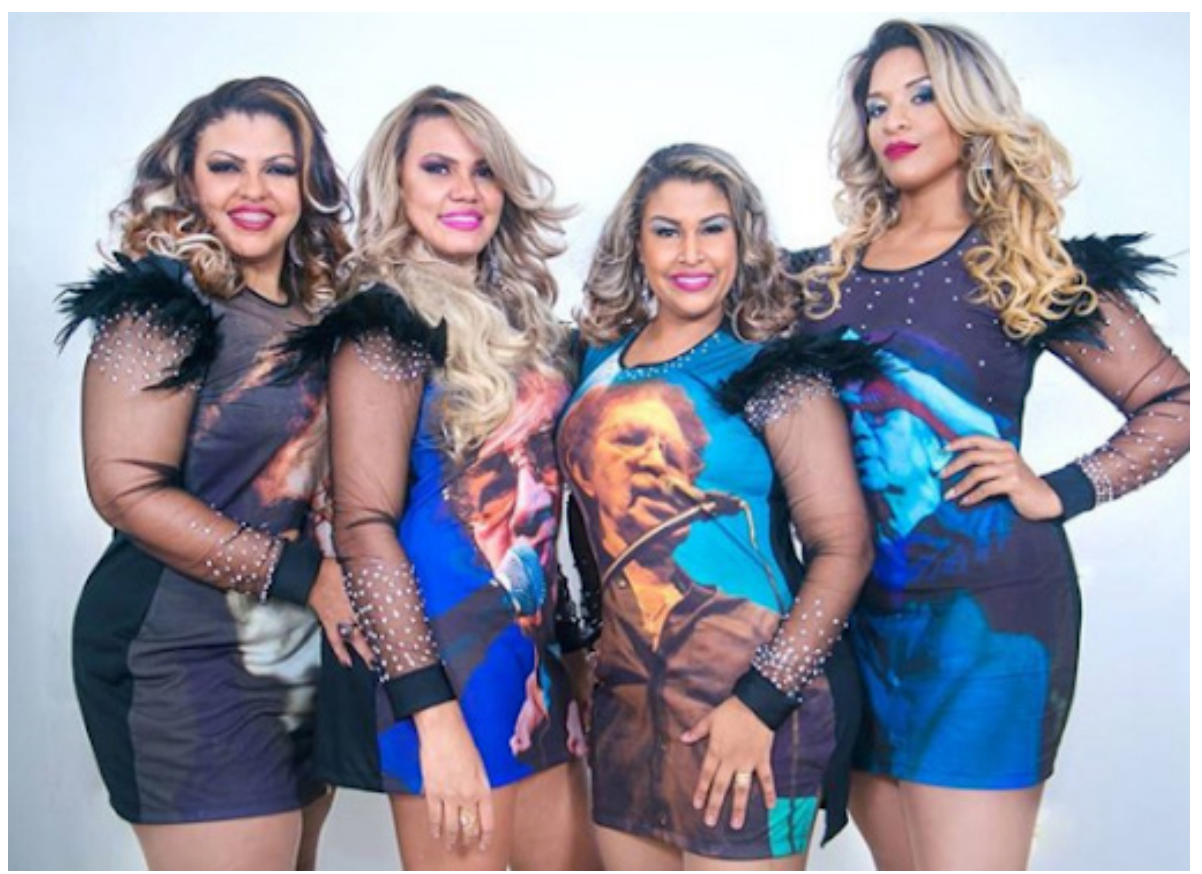

Fonte: Instagram (2021).

A performance das Amigas do Brega oscila entre aquilo que Boym (2001) chama de nostalgia reparadora e também reflexiva. Ao mesmo tempo que homenageia Reginaldo Rossi, as cantoras trazem no DVD atos performáticos com a participação de cantores mais jovens, sobretudo ligados ao bregafunk [10] - constantemente acusados de "acirrar" a competitividade entre artistas da música brega.

Nos clipes do DVD das Amigas do Brega, cada canção é liderada por uma das cantoras, com os vocais auxiliares das outras. Quando se trata de músicas que marcaram a carreira de alguma delas, a faixa é levada como solo pela intérprete original, acompanhada apenas pela banda. O espetáculo é dividido em atos, num recurso largamente explorado na música pop, com trocas de roupas e cenários (LINS, 2020). Num determinado momento do show, cada cantora veste roupas de cores diferentes, formando um "arco-íris" no palco (Imagem 2). A referência das roupas em pedrarias, tecidos e cores parecem evocar as girl bands da música pop, como as britânicas Spice Girls, grupo que gozou de amplo sucesso no final de década de 1990 instaurando globalmente a ideia do "girl power" ("poder das meninas"). Aproximar-se da ideia das girl bands implica em trazer à tona traços de uma dimensão nostálgica não somente da música brega, mas também da música pop. 


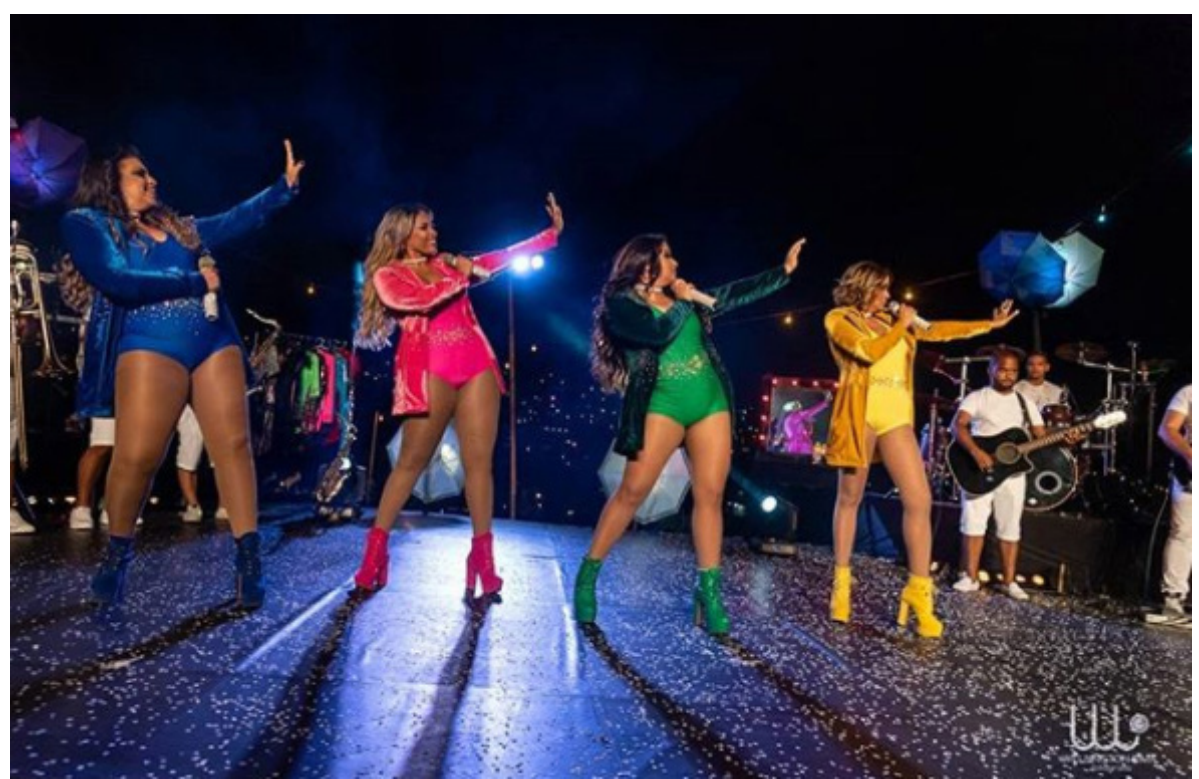

Fonte: Instagram (2021).

O formato da girl band, largamente explorado pela indústria da música pop e que, inclusive, encontrou fértil ambiente na mídia brasileira, a partir do êxito do grupo Rouge, se territorializa na periferia de Recife. Em todos os clipes divulgados para o DVD das Amigas do Brega, a marcação territorial tem papel central na plasticidade das imagens. Tomadas aéreas da região periférica do Recife (Imagem 3) com a exibição de um morro, com residências humildes numa paisagem dos altos da zona norte do Recife evidenciam a marcação territorial. Nos trechos noturnos, as luzes das casas nos morros fazem as vezes de "pano de fundo" para as cantoras.

Imagem 3 - Show é gravado em periferia da cidade do Recife.

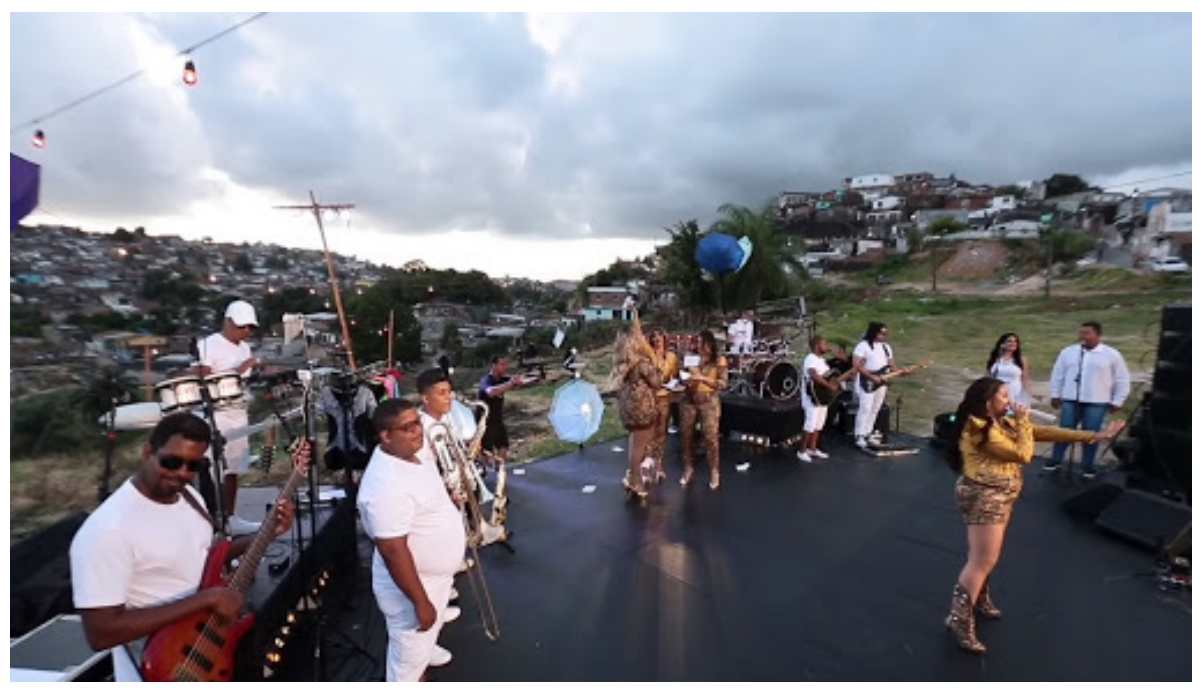

Fonte: Instagram (2021) 
Este conjunto de negociações performáticas entre as nostalgias reparadoras e reflexivas se cristaliza nos aspectos sonoros presentes no DVD. Ao mesmo tempo em que as apresentações musicais trazem à tona as marcas sonoras que consagraram a música brega romântica (o vasto uso dos teclados, as "viradas" de bateria como alicerces para o crescente dos refrões e o canto com amplo uso de extensões e vibratos, em tentativas de dramatização das letras) também aparecem as tentativas de modernização dos arranjos (através do uso de guitarras, de baterias eletrônicas) como formas sonoras e performáticas tensivas entre aspectos que reverenciam cânones sonoros do cancioneiro brega e interseções com a música pop.

\section{Considerações finais}

Ao debater o comportamento restaurado, em seus estudos sobre performances e suas atualizações no presente, Richard Schechner destaca a noção de "eficácia” como central para o entendimento das dinâmicas relacionais dos atos performáticos. Para o autor, uma performance define-se pela sua "eficácia" quando tem repercussões no tecido social, seja a partir da solução ou do tensionamento de conflitos que redefinem papéis, posições e status dos atores sociais. (SCHECHNER, 1988, p. 116). Sendo assim, cabe reconhecer que, analisando a trajetória das Amigas do Brega e o seu DVD como um marcador da eficácia performática do projeto, percebe-se que a reivindicação pela nostalgia é repleta de tensões que oscilam entre o desejo de passado e a ânsia da atualização.

O que chamamos aqui de performance de nostalgia, transitando entre arquivos e repertórios, como propõe Taylor (20013), estaria próximo ao que Derrida (2001) vai postular que "não haveria certamente desejo de arquivo sem a finitude radical, sem a possibilidade de um esquecimento que não se limita ao recalcamento" (DERRIDA, 2001, p. 32). O autor debate a possibilidade de esquecimento e suas muitas faces: o apagamento, a tentativa de borrar da história, a amnésia social ou política, o esquecimento decretado, que, no fundo, é uma contradição nos seus próprios termos. $\mathrm{Na}$ cultura arquival, fatos, coisas, acontecimentos culturais, se articulam em torno da possibilidade de corporificar arquivos, promovendo interpretações da memória cultural dos territórios em sentido mais amplo e sobre as trajetórias artísticas, de forma mais restrita.

Performar a nostalgia na música popular periférica reside em formas de negociação com o esquecimento e os diversos marcadores sociais que vão se sobrepondo nas trajetórias de artistas populares midiáticos brasileiros. Em meio a amplos processos de jovialização, os espaços de memória das manifestações populares, à revelia de ações públicas, parecem disputar a episteme mercadológica entre ações reparadoras e reflexivas - incorporando acentos, timbragens e semblantes midiáticos em que o "antigo" se construa como vintage, retrô, mas nunca como ruína ou ruga. 
[1] A Lei ${ }^{\circ} 16.044 / 2017$, proposta pelo deputado Edilson Silva (PSOL), altera a Lei ${ }^{\circ}{ }^{0} 14.679 / 2012$ e inclui o brega na lista de manifestações artísticas com espaço garantido na programação de eventos custeados pelo Estado. Para mais informações: <https://bit.ly/3Cbzfju>. Acesso em: 2 mar. 2021.

[2] Uma série de reportagens, ainda no ano de 2017, trazia à tona um questionamento sobre o status da música brega como cultura, elencando uma série de "suspeitas", como o fato do cancioneiro não ser "exclusivamente" de Pernambuco, entre outros aspectos. Mais informações: <https://bit.ly/3A40zBl>. Acesso em: 2 mar. 2021.

[3] O girl group ou girl band pauta-se na reunião de adolescentes cantoras para formar grupos musicais por produtores e consagram um formato largamente explorado na cultura pop ocidental: os grupos formados por meninos (boy bands) e meninas (girl bands). Uma história da música pop no Ocidente permite visualizar momentos em que boy bands e girl bands foram importantes mediadores para "atravessamentos culturais" (MARTEL, 2012), na busca de novos mercados e também para a incorporação de diferenças no âmbito da indústria do entretenimento. Martel (2012) lembra que uma das estratégias da gravadora Motown para promover cruzamentos culturais para consumo da música negra por plateias brancas na década de 1960, num Estados Unidos racialmente segregado foi o amplo uso deste formato de grupos de jovens negros separados por gênero. Jackson 5 e The Supremes, grupos musicais formados por jovens homens negros e mulheres negras, foram, nas palavras do sociólogo, formas de atenuar as diferenças dos corpos negros para seu amplo consumo no contexto de acirramento racial em âmbito midiático. No contexto da música brega em Pernambuco, recorrer ao formato sugere a busca por amplos mercados, ligados à música pop de forma mais ampla.

[4] O projeto Amigas do Brega foi interrompido em 27 de novembro de 2019, pouco mais de um ano depois da sua criação. De um lado, Palas Pinho, criadora do grupo e detentora legal do nome da banda. De outro, Dany Myller, Eliza Mell e Dayanne Henrique. Com a saída de Palas, as outras três artistas passaram a se intitular Amigas, enquanto a primeira decidiu, ela mesma, recriar o grupo Amigas do Brega com outras integrantes. Na ocasião da redação deste artigo, em 2021, o projeto Amigas tinha sido extinto em função de discordâncias legais e as Amigas do Brega seguiam com a cantora Palas Pinho, Fernanda Vasconcelos e Madonna Becker.

[5] Esta divisão geracional na música brega integra uma forma de enquadramento comumente utilizado por autores para agrupar artistas e narrar as oscilações, novidades e apagamentos a partir de recortes específicos. Por segunda geração da música brega de Pernambuco, entende-se o conjunto de artistas, em grande parte mulheres, que na virada da década de 1990 para 200o, se lança no mercado musical como uma espécie de "resposta" à forte presença de homens no cancioneiro brega de Pernambuco. Mais detalhes sobre as clivagens geracionais na música brega a seguir.

[6] Segundo Boym (2001), no século XVII, a nostalgia era entendida principalmente como uma doença, uma patologia que precisava ser remediada e curada e afetava majoritariamente os soldados e migrantes, como um sentimento de anseio por dias melhores que eterniza a utopia de um passado. De origem grega, a palavra "nostalgia" tem duas raízes, nostos que significa "voltar à casa" e algia, anseio.

[7] Os vídeos foram gravados pela Pro Rec, empresa de filmagens que concentra quase todo o mercado de videoclipes brega no Recife. A trajetória da Pro Rec na produção audiovisual também é importante para pensar uma outra vertente da nostalgia no brega recifense. Em 2011, a produtora, comandada pelo empresário Ítalo Monteiro, convidou a banda Swing do Amor para gravar um clipe da canção "História da Vida", uma das primeiras canções lançadas pela banda, por volta de 2004 - e se notável por "resgatar" artistas no mercado de música 
brega.

[8] Um dos principais canais do YouTube a publicar especialmente vídeos nostálgicos era o Mega Pop Recife, que reunia produções da TV Nova Nordeste, uma das emissoras locais mais identificadas com o perfil de exibição de programas ligados ao brega. Em 2015, o canal Mega Pop Recife publicou uma série de 82 vídeos de apresentações musicais no Tarde Legal, que compõem uma playlist chamada "Túnel do Tempo", dedicada a relembrar as canções que fizeram sucesso nos anos 2000.

[9] Disponível em: <https://bit.ly/3ynmOyN>. Acesso em: 9 fev. 2020.

[10] Entre os featurings presentes no DVD estão os MCs Elvis e Japão, nomes revelados principalmente após a consagração do bregafunk em 2017. Outra participação é de Raphaela Santos, da banda A Favorita, cantora bastante jovem, que alcançou notoriedade nacional também em 2017, com a música "Só Dá Tu", uma versão brega do hit estadunidense "I Got You”, de Bebe Rexha.

\section{Referências}

AMARAL, P. M. Estigma e Cosmopolitismo na Constituição de uma Música Popular Urbana da Periferia: etnografia da produção do tecnobrega em Belém do Pará. 2009. 245 p. Tese (Doutorado em Música) - Instituto de Artes, Universidade Federal do Rio Grande do Sul, Porto Alegre, 2009. Disponível em: https://ume.ufrgs.br/ handle/10183/17305. Acesso em: 7 ago. 2021.

ARAÚJO, P. G. de. Eu não sou cachorro, não: música popular cafona e ditadura militar. 7. ed. Rio de janeiro: Record, 2010.

AZEVEDO, R; JÁCOME, P; PRADO, D. Descarga acústico-visual e temporalidades em cena: a fundação de uma tradição pela Banda Calypso. Galáxia, n. especial 1, p. 47-60, 2019. DOI: <https://doi.org/10.1590/1982-25542019441661>.

BOYM, S. The Future of Nostalgia. New York: Basic, 2001.

DERRIDA, J. Mal de Arquivo. Rio de Janeiro: Civilização Brasileira, 2011.

DIAS, R. Vocês achavam que Palas estava na pior?. Folha de Pernambuco, Recife, 24 de jul. de 2011. Revista da Folha.

FONTANELLA, F. A estética do brega: cultura de consumo e o corpo nas periferias do Recife. 2005. 145 p. Dissertação (Mestrado em Comunicação) - Centro de Artes e Comunicação, Universidade Federal de Pernambuco, Recife, 2005 Disponível em: <https://repositorio.ufpe.br/handle/123456789/3455>. Acesso em: 12 ago. 2021.

GOMES, R. Amigas do Brega se reúnem para fortalecer o ritmo em Pernambuco. Jornal do Commercio, Recife, 20 de janeiro de 2018. Disponível em: <https://jc.ne1o. uol.com.br/canal/cultura/musica/noticia/2018/o1/20/amigas-do-brega-se-reunempara-fortalecer-0-ritmo-em-pernambuco-324745.php>. Acesso em: 7 ago. 2021. 
GUMBRECHT, H. U. Produção de Presença: O que o Sentido não consegue transmitir. Rio de Janeiro: Ed. Contraponto, 2010.

HOBSBAWM, E. Introdução: a invenção das tradições. In: HOBSBAWM, E.; RANGER, T. (orgs.). A invenção das tradições. Rio de Janeiro: Paz e Terra, 1997, p. 9-23.

HOBSBAWM, E.; RANGER, T. (orgs.). A invenção das tradições. Rio de Janeiro: Paz e Terra, 1997.

LINS, M. This is show business: A cultura dos megaespetáculos pop e a invenção do "padrão Madonna”. In: SOARES, Thiago; MANGABEIRA, A.; LINS, M. (orgs.). Divas Pop: O Corpo-Som das cantoras na Cultura midiática. Belo Horizonte: Fafich/ Selo PPGCOM/ UFMG, 2020, p. 165-180.

MARTíN-BARBERO, J. Dos Meios às Mediações. Rio de Janeiro: ED. UFRJ, 1997.

MELO, O. B. de; CASTRO, O. Apropriação de tecnologias e produção cultural: inovações em cenas musicais da Região Norte. In: HERSCHMANN, M. (org.). Nas bordas e fora do mainstream musical: Novas tendências da música independente no início do século XXI. São Paulo: Estação das Letras e Cores, 2011, p. 185-208.

MONTAÑO, S. Plataformas de vídeo: Apontamentos para uma ecologia do audiovisual da web na Contemporaneidade. Porto Alegre: Sulina, 2015.

PEREIRA DE SÁ, S. Cultura Digital, Videoclipes e a Consolidação da Rede de Música Brasileira Pop Periférica. Revista Fronteiras - estudos midiáticos, v. 21, n. 2, p. 21-32, 2019. DOI: <https://doi.org/10.4013/fem.2019.212.03>.

SCHECHNER, R. Between Theater and Anthropology. Philadelphia: The University of Pennsylvania Press, 1985.

SCHECHNER, R. Performance theory. New York: Routledge, 1988.

SCHECHNER, R. Restauração do comportamento. In: BARBA, E; SAVARESE, N. A arte secreta do ator: dicionário de antropologia teatral. Campinas: Hucitec, 1995, p. 205210.

SOARES, T. Percursos para estudos sobre música pop. In: CARREIRO, R; FERRARAZ, R; PEREIRA DE SÁ, S. (orgs.). Cultura Pop. Salvador: Edufba; Brasília: Compós, 2015. p. 19-33.

SOARES, T. "Ninguém é perfeito e a vida é assim": A música brega em Pernambuco. Recife: Editora Outros Críticos, 2017.

SOARES, T; BENTO, E. A Nacionalização do Brega funk. Revista Temática, v. 16, n. 6, p.207-224, 2020. Disponível em: <https://periodicos.ufpb.br/ojs/index.php/tematica/ article/view/54541>. Acesso em: 7 ago. 2021. 
SOARES, T; MANGABEIRA, A; LINS, M. (orgs.). Divas Pop: O Corpo-Som das Cantoras na Cultura Midiática. Belo Horizonte: Fafich/ Selo PPGCOM/ UFMG, 2020.

TAYLOR, D. O arquivo e o repertório: performance e memória cultural nas Américas. Belo Horizonte: UFMG, 2013. 